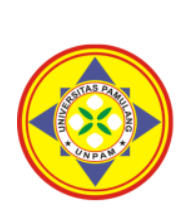
PERKUSS

\title{
PENGARUH CITRA MEREK TERHADAP KEPUTUSAN PEMBELIAN SEPATU NIKE PADA MAHASISWA UNIVERSITAS PAMULANG
}

\author{
${ }^{1 *}$ Irfan Rizka Akbar, ${ }^{2}$ Heri Erlangga, ${ }^{3}$ Jasmani, ${ }^{4}$ Riri Oktarini, ${ }^{5}$ Ade Yusuf \\ 1.3.4.5Universitas Pamulang, Tangerang, Banten, Indonesia \\ 2Universitas Pasundan, Bandung, Jawa Barat, Indonesia \\ *dosen02461@unpam.ac.id
}

\begin{abstract}
Abstrak
Penelitian ini bertujuan untuk mengetahui pengaruh citra merek terhadap keputusan pembelian sepatu Nike Pada Mahasiswa Universitas Pamulang. Metode yang digunakan adalah explanatory research dengan sampel sebanyak 90 responden. Teknik analisis menggunakan analisis statistik dengan pengujian regresi, korelasi, determinasi dan uji hipotesis. Hasil penelitian ini variabel citra merek diperoleh nilai rata-rata skor sebesar 3,418 dengan kriteria baik. Variabel keputusan pembelian diperoleh nilai rata-rata skor sebesar 3,793 dengan kriteria baik. Citra merek berpengaruh positif dan signifikan terhadap keputusan pembelian dengan nilai persamaan regresi $Y=10,457+0,804 X$, dan nilai koefisien korelasi 0,730 atau memiliki tingkat hubungan yang kuat dengan nilai determinasi $53,2 \%$. Uji hipotesis diperoleh signifikansi 0,000 $<0,05$.
\end{abstract}

Kata Kunci: Citra Merek, Keputusan Pembelian.

\section{Abstract}

This study aims to determine the effect of brand image on purchasing decisions for Nike shoes by Pamulang University students. The method used is explanatory research with a sample of 90 respondents. The analysis technique uses statistical analysis with regression testing, correlation, determination and hypothesis testing. The results of this study the brand image variable obtained an average score of 3,418 with good criteria. The purchase decision variable obtained an average score of 3.793 with good criteria. Brand image has a positive and significant effect on purchasing decisions with a regression equation value of $Y=10.457+0.804 X$, and a correlation coefficient value of 0.730 or having a strong level of relationship with a determination value of $53.2 \%$. Hypothesis testing obtained a significance of $0.000<0.05$.

Keywords: Brand Image, Purchase Decision.

\section{PENDAHULUAN}

Perkembangan ekonomi dewasa ini semakin mengarah pada persaingan ketat khususnya untuk perusahaan sejenis. Oleh karena itu, keadaan ini akan mengakibatkan perusahaan setiap kali harus selalu mengikuti perubahan, baik dalam bidang politik, ekonomi, sosial dan budaya. Selain itu, perusahaan harus mengikuti pola perilaku pesaing dalam menjalankan bisnisnya. Hal ini membuat persaingan antar perusahaan semakin ketat dalam perebutan pangsa pasar. Setiap perusahaan ingin berhasil dalam menjalankan bisnisnya. Mereka dituntut untuk memiliki suatu keunikan yang dapat memikat konsumen dalam rangka mempertahankan atau merebut pangsa pasar yang ada.

Pada zaman modern saat ini, salah satu industri yang tumbuh pesat adalah industri sepatu olahraga. Hal ini terjadi karena tumbuhnya peningkatan kesadaran masyarakat akan manfaat dari olahraga. Kenyataan ini merupakan peluang yang dimanfaatkan oleh produsen sepatu dengan mengeluarkan berbagai jenis dan merek yang dikeluarkan di Indonesia. Produsen sepatu berlomba-lomba untuk menarik minat konsumen untuk membeli produknya.

Produk industri sepatu juga sangat kompetitif dalam bentuk, warna, kecanggihan teknologi, dan merek. Merekmerek sepatu yang beredar di pasaran 
industri olahraga di Indonesia sekarang ini berasal dari berbagai negara diantaranya Amerika, Eropa dan Asia seperti Nike, Adidas, Puma, Diadora Umbro, Lotto, Kappa, Kelme, dan Joma. Merek-merek tersebut banyak diminati oleh masyarakat Indonesia. Tidak ketinggalan juga produk dalam negeri yang banyak digemari diantaranya League, Specs, dan Mitre. Setiap merek menawarkan pelayanan tersendiri untuk pelanggannya, sampai penetapan harga yang cukup bersaing sesuai dengan jenis dan segmen pasarnya.

Konsumen saat ini juga sangat kritis dalam memilih suatu produk, sampai pada keputusan untuk membeli produk tersebut. Seperti diketahui bersama bahwa tawaran produk saat ini sangatlah beragam dan banyak, tidak terkecuali untuk iklan produk sepatu mengalami perkembangan yang sangat pesat. Alternatif pilihan yang semakin banyak memudahkan konsumen untuk menentukan pilihan sesuai dengan selera dan kemampuan ekonominya. Karenanya, dengan menjaga mutu dan model, produsen dapat memikat dan membuat konsumen tersebut membeli dan loyal terhadap produk tersebut.

Keputusan untuk membeli suatu produk sangat dipengaruhi oleh penilaian akan kualitas produk tersebut. Tuntutan permintaan akan sebuah produk barang yang semakin berkualitas membuat perusahaan yang bergerak diberbagai bidang usaha berlomba-lomba meningkatkan kualitas produk yang mereka miliki demi mempertahankan brand image (citra merek) produk yang mereka miliki. Merek mempunyai sifat khas, dan sifat khas inilah yang membedakan produk yang satu berbeda dengan produk yang lainnya.

Keputusan pembelian oleh konsumen adalah keputusan yang melibatkan persepsi terhadap kualitas, nilai, dan harga. Konsumen tidak hanya menggunakan harga sebagai indikator kualitas, tetapi juga sebagai indicator biaya yang dikeluarkan untuk ditukar dengan model produk atau manfaat produk. Karenanya, melihat sejauh mana merek yang disandangkan dapat memengaruhi penilaian konsumen terhadap brand image (citra merek) dari produk tersebut.

$\begin{array}{llr}\text { Berbagai } & \text { upaya } & \text { dilakukan } \\ \text { perusahaan } & \text { dalam } & \text { rangka }\end{array}$
mempertahankan brand image yang mereka miliki diantaranya inovasi teknologi keunggulan yang dimiliki produk tersebut, penetapan harga yang bersaing, dan promosi yang tepat sasaran. Semakin baik Brand Image produk yang dijual, maka semakin tinggi keputusan pembelian oleh konsumen.

Nike merupakan merek peralatan olahraga asal Amerika yang didirikan oleh Phil Knight, seorang pelari jarak menengah dan mahasiswa akuntansi di Universitas Oregon, bersama pelatih Bill Bowerman Phil. Cinta mereka pada olahraga membuat mereka selalu bersama, dan mereka juga memiliki cinta kepada teknologi sepatu olahraga dan pakaian. Pada tahun 1987, Nike merilis model pertamanya yaitu Air Max Line. Gelembung udara (Air Bubbles) dan kenyamanannya meyakinkan banyak orang untuk membeli sepasang Air Max Line. Sejak saat itu Nike secara terus menerus melakukan inovasi baru dalam setiap pembuatan produk sepatunya. Agar setiap konsumen selalu merasa puas ketika membeli produk sepatunya, Nike suka merilis sepatu dengan bahan yang terkadang suka tidak terpikirkan oleh kompetitornya. Selain itu, Nike mempunyai gaya yang berbeda dalam mempromosikan setiap produknya. Selain menggunakan media, mensponsori klub-klub olahraga, membuka toko- toko di pusat perbelanjaan, Nike sering melakukan event olahraga yang secara tidak langsung juga mempromosikan produk-produknya. Dari berbagai kegiatan tersebut Nike mempromosikan produkproduknya agar tetap digemari oleh kalangan luas, khususnya pecinta olahraga. Dengan demikian, semakin baik brand image sebuah produk, maka semakin banyak konsumen yang tertarik untuk membeli produk tersebut.

Sasaran konsumen Nike tidak hanya masyarakat umum, tetapi juga mahasiswa. 
Nike mencitrakan dirinya sebagai sepatu yang berkualitas dan terpelajar sehingga cocok untuk kalangan mahasiswa. Banyak mahasiswa yang tertarik untuk membeli produk Nike karena brand image yang di bangun oleh Nike. Tidak sedikit mahasiswa yang menjadi pelanggan fanatik dari produk Nike. Nike berupaya menjaganya dengan melakukan promosi ke kampus, melalui sponsorsip dalam kegiatan olahraga di kampus. Nike selama ini juga mempunyai citra yang cukup baik dari kalangan masayarakat, dengan hal tersebut diharapkan mampu memberi pengaruh terhadap keputusan pembelian sepatu merek nike.

Namun demikian, belum banyak penelitian yang mengkaji tentang kaitan keputusan pembelian oleh mahasiswa dengan perkembangan brand image. Berdasarkan paparan tersebut bahwa brand image mempunyai kontribusi atau pengaruh sumbangan yang cukup dominan dalam hal keputusan pembelian seseorang terhadap produk suatu barang. Secara teoritis, faktor tersebut dapat dipertanggung jawabkan kebenarannya, namun perlu dibuktikan secara empiris bagaimana sumbangan faktor tersebut terhadap keputusan pembelian. Dari uraian diatas, maka peneliti ingin mengetahui seberapa besar pengaruh citra merek sepatu Nike terhadap pengambilan keputusan pembelian sepatu Nike pada mahasiswa Universitas Pamulang.

\section{TINJAUAN PUSTAKA}

1. Citra Merek

Citra merek merupakan serangkaian asosiasi (persepsi) yang ada dalam benak konsumen terhadap suatu merek, biasanya terorganisasi menjadi suatu makna. Hubungan terhadap suatu merek akan semakin kuat jika didasarkan pada pengalaman dan mendapat banyak informasi. Citra atau asosiasi merepresentasikan persepsi yang bisa merefleksikan kenyataan yang objektif ataupun tidak. Citra yang terbentuk dari asosiasi (presepsi) inilah yang mendasari keputusan membeli bahkan loyalitas merek (brand loyalty) dari konsumen. Citra merek meliputi pengetahuan dan kepercayaan akan atribut merek (aspek kognitif), konsekuensi dari penggunaan merek tersebut dan situasi penggunaan yang sesuai, begitu juga dengan evaluasi, perasaan dan emosi yang dipresepsikan dengan merek tersebut (aspek Afektif)

2. Keputusan Pembelian

Kotler dalam Fandy Tjiptono (2008:

20) dalam keputusan pembelian konsumen seringkali ada lebih dari dua pihak dari proses pertukaran atau pembelian. Umumpnya ada lima macam peran yang dapat di lakukan seseorang. Ada kalanya kelima peran ini dipegangoleh satu orang, namun seringkali peran tersebut dilakukan beberapa orang. Pemahaman mengenai peran ini sangat berguna dalam rangka memuaskan kebutuhan dan keinginan konsumen

\section{METODE}

Populasi dalam penelitian ini berjumlah 90 responden mahasiswa Universitas Pamulang. Teknik pengambilan sampling dalam penelitian ini adalah sampel jenuh, dimana semua anggota populasi dijadikan sebagai sampel. Dengan demikian sampel dalam penelitian ini sampel yang digunakan berjumlah 90 responden. Jenis penelitian yang dipakai adalah asosiatif, dimana tujuannya adalah untuk mengetahui atau mencari keterhubungan antara variabel independen terhadap variabel dependennya. Dalam menganalisis data digunakan uji validitas, uji reliabilitas, analisis regresi linier sederhana, analisis koefisien korelasi, analisis koefisien determinasi dan pengujian hipotesis

\section{HASIL DAN PEMBAHASAN}

1. Analisis Deskriptif

Pada pengujian ini digunakan untuk mengetahui skor minimum dan maksimum skor tertinggi, ratting score dan standar deviasi dari masing-masing 
variabel. Adapun hasilnya sebagai

berikut:

Tabel 1. Hasil Analisis Descriptive Statistics

Descriptive Statistics

$\mathrm{N}$ Minimum Maximum Mean Std. Deviation

\begin{tabular}{|l|r|r|r|r|r}
\hline Citra merek (X) & 90 & 29 & 44 & 34.18 & 3.686 \\
\hline Keputusan pembelian (Y) & 90 & 29 & 49 & 37.93 & 4.061 \\
\hline Valid N (listwise) & 90 & & & & \\
\hline
\end{tabular}

Citra merek diperoleh varians minimum sebesar 29 dan varians maximum 44 dengan ratting score sebesar 3,418 dengan standar deviasi 3,686 . Skor ini termasuk pada rentang sakala 3,40 - 4,19 dengan kriteria baik atau setuju.

Keputusan pembelian diperoleh varians minimum sebesar 29 dan varians maximum 49 dengan ratting score sebesar 3,793 dengan standar deviasi 4,061. Skor ini termasuk pada rentang sakala 3,40 - 4,19 dengan kriteria baik atau setuju.
2. Analisis Verifikatif

Pada analisis ini dimaksudkan untuk mengetahui pengaruh variabel independen terhadap variabel dependen. Adapun hasil pengujian sebagai berikut:

a. Analisis Regresi Linier Sederhana

Uji regresi ini dimaksudkan untuk mengetahui perubahan variabel dependen jika variabel independen mengalami perubahan. Adapun hasil pengujiannya sebagai berikut:

Tabel 2. Hasil Pengujian Regresi Linier Sederhana

Coefficients ${ }^{a}$

Unstandardized Coefficients Standardized Coefficients

\begin{tabular}{|c|c|c|c|c|c|}
\hline Model & B & Std. Error & Beta & $\mathrm{t}$ & Sig. \\
\hline 1 (Constant) & 10.457 & 2.760 & & 3.788 & .000 \\
\hline Citra merek $(X)$ & .804 & .080 & .730 & 10.011 & .000 \\
\hline
\end{tabular}

Berdasarkan hasil pengujian pada tabel di atas, diperoleh persamaan regresi $\mathrm{Y}=10,457+$ $0,804 X$. Dari persamaan tersebut dijelaskan sebagai berikut:

1) Konstanta sebesar 10,457 diartikan jika citra merek tidak ada, maka telah terdapat nilai keputusan pembelian sebesar 10,457 point.

2) Koefisien regresi citra merek sebesar 0,804, angka ini positif artinya setiap ada peningkatan

Tabel 3. Hasil Pengujian Koefisien Korelasi Citra merek Terhadap Keputusan pembelian.

Correlations $^{b}$

\begin{tabular}{llr|r} 
& & Citra merek $(X 1)$ & Keputusan pembelian $(\mathrm{Y})$ \\
\hline Citra merek $(\mathrm{X})$ & Pearson Correlation & 1 & $.730^{* *}$ \\
\cline { 2 - 4 } & Sig. (2-tailed) & & .000 \\
\hline Keputusan pembelian $(\mathrm{Y})$ & Pearson Correlation & $.730^{* *}$ & 1 \\
\cline { 2 - 4 } & Sig. (2-tailed) & .000 & \\
\hline
\end{tabular}

citra merek sebesar 0,804 point maka keputusan pembelian juga akan mengalami peningkatan sebesar 0,804 point.

b. Analisis Koefisien Korelasi

Analisis koefisien korelasi dimaksudkan untuk mengetahui tingkat kekuatan hubungan dari variabel independen terhadap variabel dependen. Adapun hasil pengujian sebagai berikut: 
Berdasarkan hasil pengujian diperoleh nilai korelasi sebesar 0,730 artinya citra merek memiliki hubungan yang kuat terhadap keputusan pembelian. c. Analisis Koefisien Determinasi

Analisis koefisien determinasi dimaksudkan untuk mengetahui besarnya persentase pengaruh dari variabel independen terhadap variabel dependen. Adapun hasil pengujian sebagai berikut:

Tabel 4. Hasil Pengujian Koefisien Determinasi Citra merek Terhadap Keputusan pembelian.

Model Summary

\begin{tabular}{lr|r|r|r} 
Model & $\mathrm{R}$ & R Square & Adjusted R Square & Std. Error of the Estimate \\
\hline 1 & $.730^{\mathrm{a}}$ & .532 & .527 & 2.792 \\
\hline
\end{tabular}

Berdasarkan hasil pengujian diperoleh nilai determinasi sebesar 0,532 artinya citra merek memiliki kontribusi pengaruh sebesar 53,2\% terhadap keputusan pembelian, sedangkan sisanya sebesar $46,8 \%$ dipengaruhi oleh faktor lain yang tidak dilakukan penelitian

\section{d. Uji Hipotesis}

Pengujian hipotesis dengan uji $t$ digunakan untuk mengetahui hipotesis mana yang diterima.

Rumusan hipotesis: Terdapat pengaruh yang signifikan antara citra merek terhadap keputusan pembelian.

Tabel 5. Hasil Uji Hipotesis Citra merek Terhadap Keputusan pembelian.

\section{Coefficientsa}

Unstandardized Coefficients Standardized Coefficients

\begin{tabular}{|c|c|c|c|c|c|}
\hline Model & B & Std. Error & Beta & $\mathrm{t}$ & Sig. \\
\hline 1 (Constant) & 10.457 & 2.760 & & 3.788 & .000 \\
\hline Citra merek $(X)$ & .804 & .080 & .730 & 10.011 & .000 \\
\hline
\end{tabular}

Berdasarkan hasil pengujian pada tabel di atas, diperoleh nilai $\mathrm{t}$ hitung $>\mathrm{t}$ tabel atau $(10,011>1,987)$, dengan demikian hipotesis yang diajukan bahwa terdapat pengaruh yang signifikan atara citra merek terhadap keputusan pembelian diterima.

\section{PEMBAHASAN HASIL PENELITIAN}

1. Kondisi Jawaban Responden Variabel Citra merek

Berdasarkan jawaban responden, variabel citra merek diperoleh ratting score sebesar 3,418 berada di rentang skala 3,40 - 4,19 dengan kriteria baik atau setuju.

2. Kondisi Jawaban Responden Variabel Keputusan pembelian

Berdasarkan jawaban responden, variabel keputusan pembelian diperoleh ratting score sebesar 3,793 berada di rentang skala 3,40 - 4,19 dengan kriteria baik atau setuju.
3. Pengaruh Citra merek Terhadap Keputusan pembelian

Citra merek berpengaruh signifikan terhadap keputusan pembelian dengan persamaan regresi $Y$ $=10,457+0,804 \mathrm{X}$, nilai korelasi sebesar 0,730 atau memiliki hubungan yang kuat dengan kontribusi pengaruh sebesar $53,2 \%$. Pengujian hipotesis diperoleh nilai $\mathrm{t}$ hitung $>\mathrm{t}$ tabel atau $(10,011>$ $1,987)$. Dengan demikian hipotesis yang diajukan bahwa terdapat berpengaruh signifikan antara citra merek terhadap keputusan pembelian diterima.

\section{PENUTUP}

\section{Simpulan}

1. Variabel citra merek diperoleh ratting score sebesar 3,418 berada di rentang skala 3,40 - 4,19 dengan kriteria baik atau setuju.

2. Variabel keputusan pembelian diperoleh ratting score sebesar 3,793 berada di rentang skala 3,40 - 4,19 dengan kriteria baik atau setuju. 
3. Citra merek berpengaruh signifikan terhadap keputusan pembelian dengan persamaan regresi $\mathrm{Y}=10,457+0,804 \mathrm{X}$, nilai korelasi sebesar 0,730 atau kuat dan kontribusi pengaruh sebesar 53,2\% sedangkan sisanya sebesar $46,8 \%$ dipengaruhi faktor lain. Uji hipotesis diperoleh nilai $\mathrm{t}$ hitung $>\mathrm{t}$ tabel atau $(10,011>1,987)$.

\section{Saran}

1. Bagi perusahaan produk sepatu atau toko agar lebih menjaga dan meningkatkan citra merek (brand image) sepatu Nike di masyarakat untuk memempengaruhi keputusan pembelian.

2. Bagi peneliti selanjutnya dapat dilakukan dengan merek produk lain sehingga yang teridentifikasi lebih banyak lagi.

3. Bagi peneliti selanjutnya dapat dilakukan penelitian dengan variabel bebas lain, sehingga variabel yang mempengaruhi keputusan pembelian dapat teridentifikasi lebih banyak lagi.

\section{DAFTAR PUSTAKA}

Aaker, D. A. (1991). Managing Brand Equity: Capitalizing on the value of a brand name. New York: Free Press

Abdullah, M (2014) Manajemen dan Evaluasi Keputusan pembelian, Yogyakarta: Penerbit Aswaja Pressindo.

Algifari. (2015). "Analisis Regresi untuk Bisnis dan Ekonomi". Yogyakarta: BPFE.

Arikunto, Suharsimi (2014). "Prosedur Penelitian Suatu Pendekatan Praktek". Jakarta: Rineka Cipta.

Ariyanto, A., Nuryani, A., \& Sunarsi, D. (2020). Pengaruh Store Atmosphere Dan Promosi Terhadap Keputusan Pembelian Pada Alfamart BSD Tangerang Selatan. Jurnal Ekonomi Efektif, 3(1).

Bashu Swastha dan T. Handoko (2015) Manajemen Pemasaran Moderen, Yogyakarta: BPFE.

Basu Swastha Dharmmesta. (2014). Manajemen Pemasaran. BPFE: Yogyakarta. Buchari Alma. 2014.
Manajemen pemasaran dan

Pemasaran Jasa. Edisi Revisi.

Bilson Simamora (2016) Panduan Riset

Prilaku Konsumen, Jakarta: PT. Gramedia Pustaka.

Erlangga, H. (2020). The Challenges of Organizational Communication in the Digital Era. Solid State Technology, 63(4), 1240-1246.

Fandy Tjiptono (2017), Serivce Quality and Satisfiation. Jakarta: Edisi tiga. Andi.

Freddy Rangkuti (2016) Strategi Promosi Yang Kreatif, Edisi Pertama, Cetakan Pertama Jakarta: Gramedia Pustaka Utama.

Haque, MG., Munawaroh, Sunarsi, D., (2020). Analysis of SMEs Culinary Marketing Strategy During Covid 19 Pancemic: A Study at "Sate Bebek Cilegon" Resto in Cilegon, Banten. International Journal of Education, Information Technology, and Others. Vol.3. Issue 2

Imam Ghozali (2017). "Aplikasi Analisis Multivariate Dengan Program SPSS". Edisi Kelima. Semarang: Badan Penerbit Undip.

Irmal, I., Gustiarani, E., \& Sunarsi, D. (2020). Pengaruh E-Marketing dan E-CRM terhadap E-Loyalty Pengunjung Situs Website www. Cangkirbogor. com. Jurnal Ekonomi Efektif, 2(2).

Istijanto (2014) "Riset Sumber Daya Manusia". Jakarta: PT. Gramedia Pustaka

Jasmani, J. (2018). Pengaruh Kualitas Produk Dan Harga Terhadap Keputusan Pembelian Pada PT. Baja Mandiri Di Jakarta. Disrupsi Binis, 1(1).

(2019). Pengaruh Promosi Dan Pengembangan Produk Terhadap Peningkatan Hasil Penjualan. Jurnal Semarak, 1(3).

(2020). The Influence of Product Mix, Promotion Mix and Brand Image on Consumer Purchasing Decisions of Sari Roti Products in South Tangerang. PINISI Discretion Review, 1(1), 165-174. 
(2020). Analysis of the Effect of Prices, Promotions and Products on Purchase Interest Impacts on Consumer Satisfaction of VIVO Brand Mobile Phones in South Tangerang Region. Jurnal Ad'ministrare, 7(1), 7382.

Kasmad, K., Mustakim, M., \& Sunarsi, D. (2020). Increasing Community School Interest Through Service Quality, Prices and Promotion in Vocational High Schools. Journal of Educational Science and Technology (EST), 6(2).

Kharis, Ismu Fadli (2011). "Studi Mengenai Impulse Buying dalam Penjualan Online". Semarang : Skripsi Universitas Diponegoro

Kotler dan Amstrong (2017), Prinsip-prinsip Pemasaran. Edisi Kedua Belas". Jilid Satu. Jakarta: Erlangga.

Lupiyoadi (2016) Manajemen Pemasaran Jasa, Edisi 4, Jakarta: Salemba Empat.

Maddinsyah, A., Hidayat, D., Juhaeri, J., Susanto, D., \& Sunarsi, D. (2020). Desain Formulasi Dan Implementasi Bisnis Strategik Dengan Pendekatan Business Model Canvas (BMC) Terintegrasi Kerangka Integrated Performance Management System (IPMS) Pada Koperasi Asperindo. Inovasi, 7(2), 67-76.

Mani, J. (2017). Pengaruh Persepsi Merek Dan Kualitas Pelayanan Terhadap Kepuasan Pelanggan (Studi Kasus Pada PT. Bisma Narendra Di Jakarta). Jurnal Mandiri, 1(2), 187-206.

Philip Kotler (2017) Manajemen Pemasaran, Edisi Keempat Belas, Jakarta: PT. Indeks.

Phipil Kotler dan Kevin Keller (2017) Manajemen Pemasaran, Edisi Kedua Belas, Jilid Satu, Jakarta: Erlangga.
Rao, Purba, (2012). "Measuring Consumer Perceptions Through Factor Analysis", The Asian.

Santoso, Singgih (2015). "Menguasai Statistik Multivariat". Jakarta: PT Elex Media Komputindo.

Sobarna, A., Rizal, R. M., Hambali, S., \& Sunarsi, D. (2020). Influence Make a Match Model toward Communication skills in Physical and Health Pedagogical Concept. Solid State Technology, 63(6), 1355-1363.

Sudjana (2014) "Metode Statistika", Bandung: Tarsido.

Sugiyono (2017), "Metode Penelitian Administrasi : dilengkapi dengan Metode $R \mathcal{E} D^{\prime \prime}$. Bandung: Alfabeta.

Suhartanto (2014). "Metode Riset Pemasaran". Bandung: Alfabeta

Sunarsi, D. (2020). Pengaruh Bauran Pemasaran Dan Kualitas Pelayanan Terhadap Kepuasan Konsumen Pada Giant Dept Store Cabang BSD Tangerang. E-Mabis: Jurnal Ekonomi Manajemen dan Bisnis, 21(1).

Syobar, K., Hardiyan, A., Romlah, O. Y., Yusup, M., \& Sunarsi, D. (2020). The Effect of Service Quality and Price on Purchase Decisions in Woodpecker Coffee in South Jakarta. Solid State Technology, 63(6), 1491-1504.

Y Kadarusman, D Sunarsi. (2020). Pengaruh Strategi Penetapan Harga Terhadap Peningkatan Jumlah Siswa Pada SMK PGRI Balaraja. JS (JURNAL SEKOLAH) 4 (3), 213-221

Yusuf, A., \& Sunarsi, D. (2020). The Effect of Promotion and Price on Purchase Decisions. Almana: Jurnal Manajemen dan Bisnis, 4(2), 272-279. 